\title{
O Papel da Universidade Pública hoje: Concepção e Função ${ }^{1}$
}

\section{The Public University today: Conception and Function}

\section{Afrânio Mendes Catani²}

\section{Resumo:}

O artigo analisa a concepção e a função da universidade pública na atualidade reafirmando uma perspectiva de valorização e preservação do espaço público, espaço este laico, gratuito e de qualidade. Para isto problematiza o processo de expansão predominantemente privado das instituições de ensino superior e, no tocante à universidade pública problematiza as condições em que a expansão tem se dado e as conseqüências deste processo para a qualidade do ensino. Reflete ainda sobre os desafios do trabalho intelectual e da produção do conhecimento num contexto de intensificação geral do ritmo de trabalho e ênfase exagerada em produtos.

Palavras-chave: Ensino Superior; Universidade Pública; Expansão do Ensino Superior.

\begin{abstract}
:
The article analyzes the design and function of the university at present reassuring a prospect for recovery and preservation of public space, and it means a space secular, free and quality. For this, it puts in question the predominantly private process of expansion in institutions of higher education and, for the public university presents the conditions under which the expansion has been given and the consequences of this process to the quality of education. The work also reflects about the challenges of intellectual labor and the production of knowledge in the context of a general intensification of the work and exaggerated emphasis on its products.
\end{abstract}

Key-words: Higher Education; Public

University; Higher Education Expansion.

${ }^{1}$ Conferência proferida na abertura da $21^{\text {a }}$ Semana de Ensino Pesquisa e Extensão na IV Semana de Pedagogia, setembro de 2008.

2Professor na Faculdade de Educação da Universidade de São Paulo (USP). Pesquisador do CNPq. 
Eu queria agradecer a gentileza do convite e o privilégio de estar aqui com vocês nesta $21^{a}$ Semana de Ensino Pesquisa e Extensão na IV Semana de Pedagogia e gostaria de iniciar minha fala, de caráter sociológico, numa vertente mais francesa, citando um autor que não é sociólogo, mas que ingressou no Collège de France, a instituição científica de maior prestígio na França, que é Roland Barthes. Barthes, afirma mais ou menos o seguinte: ingressar numa instituição como o Collège de France é algo meio complicado, porque é como se fosse ingressar numa academia de letras, constituindo-se em motivo de honra e de alegria. Ele diz que "a honra pode ser imerecida, porque não se sabe exatamente os mecanismos que nos levam até essa instituição, outra pessoa poderia estar lá, em seu lugar. Mas a alegria é genuína, ninguém nos tira". Então, eu estou muito alegre de estar aqui com vocês hoje, aproveitando para falar sobre isso, mas, ao mesmo tempo, apesar dos cabelos brancos, eu fico tenso nesse começo e isso me ajuda a assentar um pouco as idéias.

Com relação ao tema da presente conferência, "Papel da universidade pública hoje, concepção e função", eu tenho falado sobre isto há certo tempo, escrevendo textos, participando de debates, dialogando com sindicatos, com associações científicas e docentes e, também, com colegas que se encontram relativamente ausentes nesse debate. Eu acho que o papel da universidade pública, o tema da universidade, hoje, é um dos mais candentes e de grande relevância social, no sentido de se tentar mostrar que no Brasil, país com uma grande quantidade de alunos envolvidos no ensino desde a base do sistema até o topo, isto é, a educação superior, enfrenta-se um grande problema: cerca de 72 ou $73 \%$ dos alunos encontram-se matriculados em instituições privadas, enquanto apenas 27 ou $28 \%$ o estão em estabelecimentos públicos. A conseqüência dessa situação é que o Brasil apresenta uma das mais baixas taxas de escolarização bruta da América Latina, no que se refere à educação superior.

Eu trabalho muito com a Argentina, com o Chile e outros países latino-americanos, pois também sou vinculado ao programa de pósgraduação da América Latina da USP. Então, sempre costumo falar, quando a gente dialoga e se encontra numa relação de troca com platéias como esta, dos casos de Argentina, Brasil e Chile. A situação da Argentina é exatamente oposta a do Brasil, quando $85 \%$ das matrículas em universidades concentramse em instituições públicas; o caso brasileiro é quase o revés, pois mais de $70 \%$ da matrícula é privada. E o Chile terminou com a universidade pública no sentido como nós conhecemos, ou seja, universidade pública, laica e gratuita, pois no Chile tudo é pago, mesmo as universidades públicas são pagas.

No Chile, por exemplo, um curso de Pedagogia ou de humanidades, numa universidade pública, vai custar ao menos uns US\$ 3.500 por ano. Se compararmos tal custo com alguns colégios de elite, no Brasil, concluiremos que é até mais barato. Trabalho na USP há mais de vinte e dois anos, trabalhei na Unicamp, na Unesp, na Fundação Getúlio Vargas, ou seja, já conheço 
um pouco as coisas: eu diria que nas turmas que ministro à noite, na Faculdade de Educação da USP, se esta taxa de cerca de US\$ 3.500 a US\$ 4.000 por ano fosse cobrada, eu diria de $70 \%$ dos alunos não teriam condições de freqüentar as salas de aula.

No governo atual, em nível federal, observa-se o esforço mínimo de repor, ou ao menos de tentar repor, parte das vagas de docentes. Aconteceu uma série de problemas cruciais, se voltarmos à gestão de Fernando Henrique Cardoso. Verificase que as várias universidades federais sofreram um processo de congelamento dos recursos a elas destinados, não havendo, praticamente, a reposição de recursos humanos e materiais.

Nós vamos sistematizar estas questões aqui com vocês, mas, fundamentalmente, necessitamos de um parâmetro inicial para a discussão, que é o seguinte: a universidade tem que possuir um caráter público, necessita adotar o modelo "humboldtiano", ou seja, a universidade que conhecemos hoje de ensino, de pesquisa e de extensão. Quando vemos anúncios de jornais e quando lemos a respeito das provas de desempenho do SINAES, algo é evidente: encontramos poucas instituições privadas com bom índice de aproveitamento. Entretanto, com as exceções de praxe, a maioria das IES privadas realiza apenas alguns trabalhos de extensão, quando o faz. Então, basta acompanharmos isso, observarmos o tamanho das universidades: o setor de Educação da UFPR compreende 5.000 alunos; a Universidade de São Paulo, a maior universidade pública do país em termos de alunos de graduação, não alcança 70.000 alunos; é muito pouco: a Universidade do México tem 400.000 alunos, a Universidade de Buenos Aires possui perto de 260.000. Assim, o engajamento da universidade pública brasileira ainda é muito pequeno, no sentido de dotações orçamentárias e de políticas mais agressivas de inclusão de distintos contingentes de alunos que ainda não se inseriram nessas IES.

Nos dias atuais, no Brasil, vigora certo discurso que afirma que nosso modelo de universidade de elite de alguma maneira fracassou, porque temos muitos doutores, e grande parte dos doutores não se encontram empregados. Essa é uma das maiores falácias que a gente escuta. Claro que o número de doutores aumentou, eu acabei de escrever, com Ana Paula Hey, um artigo baseado em pesquisa que desenvolvemos sobre o tema para a revista da Associação de Docentes da Universidade de São Paulo (ADUSP). A associação encomendou a um jornalista uma longa reportagem sobre isso, e vemos que a maioria dos doutores brasileiros, quando se insere no mercado, o faz em universidades públicas - mas muitos não conseguem emprego com o título de doutor. Há toda uma rede privada que, em geral, possui qualidade medonha. Nossos colegas doutores, que estão nos órgãos governamentais, não têm força política para tentar alterar tal situação, para exigir que estas universidades contratem doutores, contratem pessoas mais qualificadas. Nas regulamentações jurídicas vigentes, se as universidades tiverem $1 / 3$ de mestres e doutores (na verdade, a quase totalidade de mestres), já é o suficiente para o cumprimento da legislação.

O professor Luiz Antônio Cunha escreve artigo que é muito interessante e que eu sempre gosto de frisar quando discutimos acerca da universidade: a questão do público e do privado. Até há quinze ou vinte anos, o que era público ou privado constituía-se em dimensão bem tranqüila: público vinha a ser aquilo que era gratuito e privado aquilo pelo qual nós pagávamos. Em geral, as universidades católicas, algumas universidade metodistas, presbiterianas ou luteranas, como outras instituições isoladas, possuíam "boa qualidade"; grande parte das IES públicas também. O que Cunha nos mostra é que essa fronteira entre o público e o privado vem a ser uma fronteira em movimento, principalmente se nos referirmos à pós-graduação. No início dos processos de avaliação mais amplos, os reitores e pró-reitores dessas IES diziam algo mais ou menos assim: "Nós somos contra esse sistema de avaliação tal como está montado, pois ele não reflete o que são de fato as instituições; desenvolvemos 
uma série de atividades que não podem ser mensuráveis através de planilhas e formulários etc. etc.". Quando as avaliações são divulgadas e várias instituições privadas começam a ser razoavelmente avaliadas, estes reitores ficam quietos e participam do jogo. Isso se observa, em especial, no que se refere aos programas de mestrado e de doutorado, que recrutam professores aposentados das universidades estaduais e federais e contratam para dar aula na pós-graduação. A gente brinca que são professores de cursos de pós-graduação para a terceira idade, com professores mais velhos, que já desempenharam o seu papel durante décadas. Vão para tais programas e recebem outro salário.

E a qualidade é medida por "produtos", ou seja, o número de defesas de teses e de dissertações junto aos programas de pósgraduação, através de publicações de docentes, de mestrandos e de doutorandos, tudo em revistas indexadas e classificadas. O campo da educação superior possui grande legitimidade e, nos últimos quinze anos, aproximadamente, teve que se adaptar a uma série de obrigações, envolvendo uma legislação complexa e sofisticada, experimentando modificações absolutas nos critérios de avaliação (com as agências atuando de forma bastante rigorosa), com aposentadorias precoces em razão da possível perda, por parte dos docentes, de vantagens e conquistas previdenciárias etc. Em suma, ocorreu (e está ocorrendo) um profundo processo de renovação no campo da educação superior brasileira.

Quando ingressei na pós-graduação para realizar o mestrado na USP, era possível demorar de cinco a oito anos; o doutorado se desenvolvia, em média, durante sete a oito anos. Então, demorava-se cerca de quinze anos para se ficar doutor. Hoje eu tenho alunos bem jovens, que foram bolsistas de iniciação científica, no mestrado receberam bolsas das agências de fomento, terminaram o mestrado e fazem o doutorado com bolsa. Não estou criticando isso, só estou mostrando como é a dinâmica para a obtenção dos títulos. Os doutorandos efetuam um sanduíche no exterior, isto é, um estágio de seis meses a um ano, ou em Portugal, ou na França, ou nos Estados Unidos, ou na Inglaterra, por exemplo. Dependendo da sua pesquisa, em média voltam em três anos, no máximo quatro, concluem seus doutorados, ou seja, com vinte e sete ou vinte e oito anos. Nesse sentido, isso se modificou por completo a partir do momento da vigência dos mestrados com a duração de dois ou três anos e com os doutorados durando no máximo quatro. Então, há um público mais jovem e mais sedento para realizar o próximo trabalho. Assim, a re-configuração do campo é plena, havendo um debate cada vez mais intenso. Ocorre uma profusão do número de eventos, congressos e simpósios, de revistas e de publicações, algo impensável, talvez, há pouco mais de uma década. Bem, isso posto, qual tem sido o papel da universidade?

Recupero algumas idéias que venho desenvolvendo. Voltaria a uma velha frase, de mais de sessenta anos, de autoria do professor Antonio Candido: "Cada um com as suas armas. A nossa, dos intelectuais, é essa: esclarecer o pensamento e colocar ordem nas idéias". Essa postura continua atual. Pierre Bourdieu problematiza um pouco mais tal colocação, quando em 1993 recebeu a "Medalha de Ouro" do CNRS, na França. Todo mundo esperando que ele fizesse um discurso de agradecimento protocolar, veio uma pedrada. Ele disse que estava muito feliz por receber a medalha do CNRS, mas, ao mesmo tempo, aproveita para protestar contra a insuficiência dos meios necessários para que os pesquisadores possam desenvolver suas pesquisas com certa tranqüilidade. Declara que os novos pesquisadores e vários de seus colaboradores enfrentavam intensas dificuldades no exercício de seu métier, cobrando dos poderes públicos uma maior quantidade de recursos e investimentos na formação e na manutenção de um amplo corpo de pesquisadores. Afirma algo que considero uma preciosidade, retirada de obra clássica de Max Weber, para quem o cientista, o pesquisador, deveria muitas vezes 
responder às expectativas grandiosas e entrar no papel impossível, e um pouco ridículo, de "pequeno profeta privilegiado e estipendiado pelo Estado". Profeta desarmado, evidentemente, com a função fundamental de exercer a crítica, de criticar os processos de dominação vigentes. E a dominação, em grande medida, se dá através (e pelo) do Estado. Ou seja, nós recebemos do Estado para criticar o Estado. Isso é sempre uma relação tensa, contraditória, os poderes constituídos não suportam isso, cortam verbas, demitem e perseguem intelectuais e pesquisadores.

O grande problema que se enfrenta, muitas vezes, é a ausência de verbas, de condições de trabalho dignas. Mas deve-se chamar a atenção também para outra dimensão: eu, na qualidade de professor universitário, dentro de minhas áreas de especialização, sou analista de políticas públicas. Nesse sentido, em boa parte das vezes, vou de encontro, no sentido de colidir, com as diretrizes de políticas de governo. No domínio da área de políticas educacionais, por exemplo, há uma zona bastante confusa entre o analista de políticas e o autor de políticas, o policy maker. Eu trabalho num departamento, na Faculdade de Educação da USP, em que grande parte dos nossos colegas formula políticas para o Estado, na qualidade de consultor, assessor, no exercício de cargos políticos de confiança. Nenhum problema quanto a isso. Há apenas um detalhe: aquele que formula, desenha ou executa políticas, deixa de ser analista. Não dá para ser sociólogo-analista de políticas e executor, assessor, secretário, professor ao mesmo tempo. É o mesmo caso, entendo, de jornalistas que se tornam assessores de imprensa de governos, isto é, estão diretamente vinculados ao exercício do poder. Então, vemos situações meio constrangedoras, de colegas que se tornam executivos e analistas do "dever ser". Para mim é impossível que alguém seja analista e assessor de governo ao mesmo tempo. Quando Fernando Henrique Cardoso disse (ou the atribuíram, pouco importa) a famosa frase "Esqueçam o que eu escrevi", criticada por todos, talvez tenha sido, mesmo às avessas, uma das falas mais lúcidas que alguém poderia ter dito. Isso porque, entendo, "fazer política" possui natureza completamente distinta do que vem a ser a análise da mesma. Fazer política é organizar o espaço dos possíveis, é lidar com limitações, com esferas desiguais, com alianças ou agentes contraditórios. E isso é totalmente diferente da atividade acadêmica, da crítica social, que possui grande dose de intolerância, acidez e ironia, que recupera frases, procedimentos, contextualiza e aponta contradições dos discursos e ações políticas (e dos políticos).

Bourdieu vai mostrar essa dimensão em várias de suas obras. A universidade sempre enfrenta, à sua maneira, os governos estabelecidos, se não de forma direta, institucional, mas através das tomadas de posição políticas de parte de seus docentes e pesquisadores. É claro que a universidade acaba sendo de alguma maneira lenta em suas reações, ela tem problemas de organização muito grande, é pesada, há distintas concepções que se chocam constantemente. É por isso que eu gosto muito de algumas falas ou concepções que não são necessariamente oriundas de engajamentos políticos profundos, mas são conseqüentes e procuram ou tentam colocar a universidade no centro do debate social. Eu cito o antropólogo Marcel Mauss (1872-1950), sobrinho e discípulo de Émile Durkheim. Mauss tem uma frase genial, que se aplica como uma luva ao nosso debate: "Em matéria de ciências nenhuma lentidão é suficiente; em matéria do prático, não se pode esperar".

Retomo esse aspecto no final de minha conferência. Mas o importante, no momento, é ter em mente que se formos perder pontos ou se vamos ser demitidos, com base nos sistemas de avaliação vigentes, que regulam a produção acadêmica, que podem nos considerar "improdutivos", nós sentamos e escrevemos, publicamos e até poderemos ser considerados cientistas ou pesquisadores adequados. Entretanto, isso não significa necessariamente que estamos fazendo boa ciência. Por outro lado, há colegas que dizem estar há anos e anos 
escrevendo determinado livro ou desenvolvendo um projeto de pesquisa, sem apresentar qualquer forma de resultado. Tal postura também não é garantia de que vão sair excelentes resultados dessa maneira de trabalhar. Todavia, há uma série de pesquisas ou trabalhos de investigação que são impossíveis de se fazer em um semestre ou mesmo em um ou dois anos. Cito experiência que vivenciei. No período aproximado de 1977 a 1982, realizei uma série de coletas de material empírico sobre o campo cinematográfico paulista na década de 1950. Fiz o mestrado e o doutorado com esse material, bem como escrevi dezenas de capítulos de livros e artigos em periódicos, além de dois outros livros. Ou seja, mais de vinte e cinco anos depois, ainda tenho condições de continuar escrevendo e estudando aspectos da história do cinema brasileiro. Isso apenas foi possível em razão de eu haver recebido, no período, bolsas e auxílios financeiros da FAPESP, do CNPq, do Núcleo de Pesquisas e Publicações da Escola de Administração de Empresas de São Paulo, da Fundação Getúlio Vargas (NPP - EAESP/FGV) e da CAPES. Eu tinha entre vinte e quatro e vinte e nove anos e cheguei a contar com quatro auxiliares de pesquisa, cujo trabalho foi imprescindível para a reunião de uma vasta documentação. Bem, se as agências tivessem me cobrado de imediato os "produtos" que eu supostamente deveria ter produzido na época, eu não estaria aqui hoje. Ou seja, há trabalhos marcados pelas características da longa duração, de que fala o historiador francês Fernand Braudel. Hoje, em história do cinema, há excelentes trabalhos acadêmicos, mas são bem centrados, bem demarcados, em que são analisados uns poucos filmes, uma película, um periódico, um tema no interior de alguma publicação, poucas entrevistas realizadas etc. As cobranças das agências de financiamento são quase que imediatas e, em no máximo quatro anos, qualquer pesquisador é obrigado a doutorar-se.

Em suma, formar alguém para seguir a carreira acadêmica é um processo lento, dotado de incertezas, sendo necessária muita dedicação e certo investimento. Um exemplo bem concreto do que estou afirmando tivemos aqui hoje, nesta sala, antes de eu iniciar minha conferência: na apresentação do quarteto de cordas, que aqui estava acompanhado de um quinto elemento, o regente foi claro nas palavras que trocou conosco, ao indagar: "quanto tempo demora para se formar um quarteto de cordas? Quanto tempo demora para que ele possa se apresentar?" Ele mesmo respondeu: uns dez ou doze anos. E, nesse espaço de tempo, quem banca os estudos? Como isso se dá? Estamos diante de problemática semelhante, portanto: são necessários ao menos doze anos para se lapidar um futuro docente-pesquisador. Ele necessita desenvolver seus projetos, obter os títulos de mestre e doutor, participar de simpósios e congressos, preparar-se para o aprendizado de línguas estrangeiras, custear viagens, redigir montões de papers, realizar intercâmbios etc.

Entendo que outro ponto a merecer destaque na presente conferência refere-se ao chamado Processo de Bolonha. Não estou querendo dizer que haja reflexos imediatos e automáticos no Brasil. Entretanto, gradativamente, já estamos a enfrentar uma espécie de Bolonha à brasileira. Quando comento isso alguns colegas dizem que estou exagerando ou mesmo vulgarizando, que as coisas não são bem assim. Mas vamos em frente: em que consistem exatamente os acordos de Bolonha? Seria a constituição de um espaço europeu de educação superior criado com a finalidade de enfrentar seu similar anglosaxônico, em especial as universidades norteamericanas. Seria uma espécie de "frente única acadêmica", tentando conter a invasão norteamericana, ou seja, unindo a Europa de várias maneiras, quer os países da União Européia e muitos outros que a ela não pertencem, englobando, creio, quarenta e cinco países, de tal forma que até 2010 todos os currículos e sistemas de avaliação de tais nações seriam homogeneizados, com o objetivo de se criar um padrão de comparabilidade. Isso é necessário para que essa comparabilidade seja viável. Eu sou formado, por exemplo, em Pedagogia 
pela UFPR e tenho uma média final, digamos, "9,0". Outro aluno gradua-se ou licencia-se numa universidade que ninguém nunca ouviu falar, dessas que existem aos montes por aí, com a média 9,8. Então como é que você vai estabelecer comparações sem a existência de currículos e sistemas de avaliações idênticos?

Temos também a educação a distância, que se desenvolve a passos largos. E desses projetos que estão sendo implementados, muitos são "poupadores de mão-de-obra". Vejam, eu não sou contra a educação a distância; o que nós temos que estar atentos é que a educação a distância é música para os ouvidos do setor privado de ensino e, também, de vários segmentos das políticas educacionais públicas. Para o setor privado é um negócio altamente lucrativo; para o setor público, com poucos recursos é possível aumentar enormemente as estatísticas referentes às matrículas.

A educação a distância, no mundo todo, é utilizada como uma modalidade didática complementar. Em alguns momentos, por exemplo, de um curso de graduação, poderia ser utilizada a educação a distância para se acompanhar uma conferência determinada ou seguir ao vivo um dado acontecimento que possa ter relevância pedagógica. Ou então, para que se realizasse revisão de aprendizagem. Mas não é isso que o pessoal deseja: o pessoal quer percentuais de carga horária presencial e percentuais de carga horária a distância, com a remuneração de tutores, mais baixa que a de professores. No sistema de Bolonha, por sua vez, também estão previstas aulas a distância, ministradas por tutores ou, às vezes, por professores. Detalhemos isso um pouco mais.

Tradicionalmente, nas IES brasileiras, se você assiste a uma disciplina com carga horária semanal presencial de 4 horas, durante 15 semanas, em nível de graduação, a ela será atribuído um total de 4 créditos - é isso que vigora no país, de maneira geral. A concepção de Bolonha é distinta. Vamos pensar em um caso hipotético. Para você cursar a disciplina Sociologia I, por exemplo, devem ser satisfeitas uma série de exigências. Será preciso assistir a 20 horas-aula presenciais, dedicar 40 horas às leituras de conteúdo, elaborar uma monografia ou dissertação temática (que também irá Ihe exigir um determinado número de horas, aí compreendendo uma parcela de tempo para o trabalho de campo), além de comparecer a encontros presenciais de tutoria, em pequenos grupos, a princípio com o professor da disciplina, bem como acompanhar aulas na modalidade de educação a distância. Computando-se tudo isso se obtém um determinado valor, cuja unidade de aferição denomina-se European Credit Transfer and Accumulation System (ECTS), que obedece a regras de contabilização precisas. Bem, nada contra tal modalidade, talvez este tipo de avaliação e de concepção reflita de maneira mais fiel o efetivo trabalho dos alunos. Todo o tempo brigamos com os procedimentos do ensino privado, que em geral remunera apenas e tão somente pelo trabalho desenvolvido em sala de aula, não remunerando pesquisa, preparação, correção de exercícios, atendimento a alunos etc. Mas há outra dimensão a se ponderar: a carreira acadêmica se faz, basicamente, através de publicações e de desenvolvimento de projetos de pesquisa. Nós não somos avaliados por nossa carga didática: se dermos aula, tudo bem, não acontece muita coisa; se não dermos, aí teremos problema.

Nesse sentido, os acordos de Bolonha estabelecem encontros presenciais de tutoria, em pequenos grupos que, ao invés de ter seis ou oito alunos, já se fala, em Portugal, em vinte alunos. Ora, os professores "não têm tempo" para essa atividade, de baixo valor para a sua carreira, não dedicando muito tempo a isso. Os quatro encontros semestrais previstos originalmente, passam a ser dois; quando ocorrem mais encontros, quem cuida disso são monitores, não é o professor. O professor Licínio C. Lima, da Universidade do Minho, Portugal, escreve um artigo chamado "Bolonha à portuguesa?", no qual retoma a expressão bem conhecida nossa, "para inglês ver?", que usamos para seguir com as coisas como eram antes, mas revestidas de 
certa aparência de fachada. Mas penso que o aspecto da gratuidade, que existia nos sistemas educacionais francês e alemão, foi para o espaço. Hoje toda a concepção do curso é feita na base de três anos, como se equivalendo a um curso superior básico; mais dois anos e teríamos o equivalente ao mestrado e outros três mais ao doutorado. Portanto, em oito anos, isto é, aproximadamente dos 18 aos 26, o aluno sairia com o seu título de doutor.

Quais são os agravantes disso? A universidade, que em muitos lugares era praticamente gratuita, hoje tem um custo que deixou de ser simbólico. Não é uma coisa de outro mundo, mas se cobra entre 700 e 920 euros por ano. A pós-graduação, equivalendo ao mestrado, em dois anos, e que quase ninguém recebe bolsa, custará entre 2.000 e 2.500 euros/ ano (e a maioria dos mestrados são mestrados pagos). Para o doutorado existem bolsas, sendo que esse custo oscila aproximadamente entre 8.000 e 9.000 euros/ano; as bolsas, entretanto, não cobrem todo o valor. Então, um aluno que faz o seu doutorado, ao longo de três anos, gastará de 1.200 a 1.500 euros/ano.

Portanto, esse espaço de educação superior para os alunos que contam com alguns recursos próprios ou familiares, é uma excelente oportunidade para interagir com outras comunidades, com estudantes e colegas de outros ou de vários países, uma vez que facilita sobremaneira a realização de intercâmbios e estágios em distintos pontos da Europa. Entretanto, não se pode esquecer que é necessário um montante razoável de capital econômico para tal. Temos um amigo querido, que trabalha no norte de Portugal, cuja filha saiu do país e foi estagiar na Holanda, na área de biologia, durante seis meses. A bolsa e o auxílio que ela recebeu, cobriu apenas um mês e meio de sua permanência, o restante a família teve que bancar. Para quem tem condições financeiras, é muito bom; para quem não tem, a coisa piora, e muito, na hora de disputar um posto no mercado de trabalho. Em suma, creio que o desafio vai ser grande para esse modelo europeu de educação superior, a partir do momento em que ele começar a se consolidar. Aqui na periferia vamos ter isso como referência de alguma maneira.

$\mathrm{Na}$ realidade, já estamos vendo uma espécie de Bolonha à brasileira por aqui, representada, por exemplo, pela chamada "Universidade Nova", que agora está perdendo a força, originária da Universidade Federal da Bahia e, principalmente, com o Programa de Apoio aos Planos de Reestruturação e Expansão das Universidades Federais (REUNI). A única possibilidade, praticamente, das universidades federais obterem recursos adicionais é através do REUNI, que implica na assinatura de um termo de adesão voluntária de cada IES federal. É aquela situação: é ruim se aderir; se não aderir pode ser pior; então, todas elas acabam elaborando seus planos de reestruturação e expansão.

ComoREUNI desapareceaidéia dareposição da vaga docente da forma tradicional: quando um determinado professor se aposentava, o diretor de centro, a congregação, o reitor, todo mundo começava a gritar, a brigar para que a vaga desse professor fosse reposta, pois não era algo líquido e certo: o professor saiu ou morreu e, automaticamente, não aparecia outro no lugar. Era uma luta dos diabos. Nos governos de Fernando Henrique Cardoso a vaga não aparecia, e o máximo que se conseguia era um docente substituto, recebendo parcos proventos, dando montões de aulas e não fazendo pesquisa. Pela forma como o REUNI se estruturou, cada professor que está na ativa possui o seu valor equivalente. Assim, um docente com muitos anos de casa, que já é doutor, tem publicações, dedicação exclusiva e tudo o mais, deve valer algo como 1,55 ou 1,60. Alguém que é recém-doutor, talvez possa valer, por exemplo, 1,2; quem acabou o mestrado vai valer menos ainda, e assim por diante. Então, quando se aposentam dois professores que valem 1,6 cada um, com base no REUNI, se o Ministério da Educação autorizar a reposição de ambas as vagas, teríamos 3,2 unidades a serem repostas. Ora, se um mestrando valer, 
digamos, 0,4, é bem provável que se opte por oito mestrandos para que a carga horária seja coberta com folga. Enquanto os dois docentes mais experientes, que teriam condições de desenvolver uma nova área de investigação ou realizar projetos de ponta, além de ministrarem seis turmas, certamente seriam preteridos em função dos oito mestrandos, que ministrariam, digamos 24 turmas. Então a tendência é fazer o quê? Pegar gente menos qualificada e muitas vezes sem jornada integral de trabalho. Claro, sabemos de casos de algumas unidades que os órgãos colegiados optaram por obter menos vagas, mas contar com docentes e pesquisadores mais qualificados. Mas essa, infelizmente, não é a regra.

Na Inglaterra, por exemplo, há instituições de educação superior que estão fazendo os seus ajustes. A Universidade de Leeds, por exemplo, desativou um Centro de Estudos Ibéricos, ou seja, que trabalhava com o espanhol como primeiro idioma, alocou alguns de seus professores e despediu os demais. Tenho um amigo que foi colocado na rua aos 56 anos, ou seja, foi aposentado com base na proporcionalidade da previdência inglesa, reestruturada pelo Anthony Giddens e companhia, recebendo $32 \%$ do seu antigo salário. A universidade opera uma reengenharia em seu espaço físico e utiliza suas instalações para outras finalidades: cursos de educação a distância com um percentual das aulas sob a modalidade presencial, fazendo com que as pessoas estejam lá em fins-de-semana, utilizando os espaços dos departamentos e centros "não lucrativos" transformados agora em alojamentos ou salas interativas. $E$ algo semelhante anda ocorrendo em Portugal, sendo que algumas universidades começaram a dispensar ou a não renovar os vínculos de docentes contratados por tempo determinado, com avisos prévios e tudo o mais. Isso em universidades públicas.

$\mathrm{Na}$ Espanha podem ser observadas reações, pois o país possui um ciclo distinto, em termos de duração, para a formação universitária, não sendo possível, argumentam, reduzir o primeiro ciclo de quatro para três anos, como estabelece Bolonha. Vários sindicatos de professores, bem como o sindicato nacional do país, haviam desencadeado forte oposição a esse estado de coisas, há cerca de um ano. Sinceramente, hoje não disponho de informações confiáveis a respeito. Mas os informes, divulgados por acadêmicos de bom nível, davam conta de que se Bolonha for implementado como se prevê originalmente, haveria um desemprego de, no mínimo, $15 \%$ a $20 \%$ dos professores que estavam em atividade.

Penso eu que nosso desafio, hoje, é o papel que a universidade pública deve desempenhar. Defendo uma idéia que Pierre Bourdieu defendia, através da Association de Réflexion sue les Enseignements Supérieures et la Recherche (ARESER), que congregava vários pesquisadores e intelectuais da França. Essa Associação de reflexão sobre ensinamentos superiores e a pesquisaeditouvárioslivrosacercadauniversidade francesa e os dilemas que ela enfrentava. 0 que eu entendo, evidentemente sem fazer uma transposiçãomecânicadosdocumentosfranceses para a situação brasileira, sobre o nosso papel enquanto docentes e profissionais universitários é, de início, uma luta intensa pela valorização e preservação do espaço público, espaço esse laico, gratuito e de qualidade (ou de excelência). Uma luta necessita ser desencadeada para que se editem boas publicações, obras clássicas a preços extremamente reduzidos, e que fossem amplamente difundidas; que tivéssemos professores bem preparados, que mantivessem seus grupos de pesquisa, absorvendo boa parte dos alunos, graduandos, mestrandos e doutorandos, mas que também houvesse espaço para aqueles professores que também realizam trabalho de qualidade, mas são ensaístas. Ainda existe muita gente boa que trabalha desta forma. Ou seja, a universidade necessita abranger toda uma diversidade de comportamentos e de concepções que não se encontra em outras instituições. Em essência, é um espaço que, embora com todos os problemas que se enfrenta, dificilmente alguém vai encontrar em outro espaço 
certos graus de liberdade, como na universidade. Vamos qualificar um pouco o que nós chamamos de liberdade. Há um lado burocrático da universidade que se torna chato e desagradável, que são as provas, os trabalhos, a obrigatoriedade de cumprir uma grade curricular que nem sempre tem sentido (ou é assim entendido). Em suma, todo esse conjunto de tarefas e de obrigações, que qualquer pessoa que tenha passado pela universidade sabe do que estou falando, se constituem em constantes pontos de tensão e de conflito. Tudo isso ocorre, gerando, por vezes, uma grande antipatia pela instituição universitária. Todavia, simultaneamente, é possível encontrar tomadas de posição teóricas, acadêmicas ou mesmo políticas, distintas e contraditórias, que não são freqüentes em outros espaços. Vou fornecer um exemplo bastante concreto: eu dava aulas na USP, para as turmas de Pedagogia e, numa determinada classe, havia um professor que ministrava uma disciplina que era o equivalente à metodologia de pesquisa. O curso era o mais positivista possível, era terrível, do meu ponto de vista. Mas havia também psicologia, lecionada por um freudiano (no ano seguinte era um lacaniano). Havia na grade curricular gente com concepções behavioristas, eu ministrava seminário sobre a introdução do taylorismo em vários países etc., além de outros historiadores, sociólogos, práticos de ensino... Ou seja, a diversidade (e a liberdade) era grande, com o confronto de várias escolas de pensamento. Acredito que é dessa maneira que se deve dar a formação intelectual, no caso, dos futuros professores.

Quando vocês se graduarem, ou se licenciarem, se não forem fazer mestrado ou doutorado, deverão enfrentar de imediato o mercado de trabalho. As organizações ou instituições não vão pagar a ninguém para experimentar, para ver se dá certo ou não, para testar algo. A atuação de vocês raramente poderá conviver com o erro. Assim, entendo que a universidade ainda é esse espaço de liberdade, você ainda tem condições, de alguma forma, de mergulhar em alguns temas, pode discuti-los, aprofundá-los.
Assim, encaminhando para o final de minha fala, recupero algumas linhas gerais de meu pensamento sobre o tema da presente palestra. A meu juízo, a universidade deve ter voz ativa na sociedade, ela não pode simplesmente atender às demandas do mercado de maneira automática, porque não é preparada ou estruturada para isso. Mas ela pode, entretanto, dialogar com o mercado, uma vez que possui competência para isso, ela gera conhecimento de ponta. Mas ao mesmo tempo, ela necessita de um processo de longa duração para que tal conhecimento seja produzido e para formar um bom pesquisador. Aquilo que falamos anteriormente é um processo lento e custoso. Em algumas áreas do conhecimento, talvez uma formação mais "rápida" possa ocorrer, mas em humanidades eu não vejo como. As pessoas são formadas em processos dotados de longas sedimentações, lentamente. Alguém que começa a tocar violão, no início, tem que colocar esparadrapo nas mãos; depois, aos poucos, o calo vai se formando...

Retomo, agora, a frase de Marcel Mauss: "em matéria de ciências nenhuma lentidão é suficiente", ou seja, isso nos remete à idéia de longa duração, das sedimentações constantes e incessantes, sendo a pesquisa acadêmica necessariamente metódica e sistemática; "em matéria do prático, não se pode esperar", isto é, a universidade deve estar preparada para dialogar com a sociedade que a financia, interagindo com os seus saberes especializados, qualificados, em geral, de ponta. Em sua aula inaugural no Collège de France (março de 2002), para a cátedra de História moderna e contemporânea do político (o título de sua aula, posteriormente editada, é Por uma história conceitual do político), Pierre Rosanvallon amplia essa interpretação. Afirma que ele se preocupa com o fato de que tal distinção, estabelecida por Mauss, não pode ser abolida sem prejuízos para a ciência e para os pesquisadores. Entende-se que se corre um grande risco "de ver desaparecer a diferença entre o trabalho paciente e o comentário apressado, em uma palavra, entre a ciência e 
a opinião (...) O trabalho científico mais rigoroso e as aquisições mais pacientes da erudição participam diretamente da atividade cidadã, nascem da confrontação com o acontecimento e permanecem ligados a ele. Pretendo inscreverme, com modéstia, mas também com uma firme determinação, na linha daqueles sábios que foram também por sua própria obra de incansáveis cidadãos e não se deram trégua em esposar o pessimismo da inteligência com o otimismo da vontade, para retomar uma expressão de Romain Rolland, popularizada por Gramsci, que serviu durante muito tempo de guia a uma grande parte de minha geração."

Muito obrigado.

\section{Referências Bibliográficas}

ARESER (Association de réflexion sur les enseignements supérieures et la recherche). Quelques diagnostiques et remèdes urgents pour um université en péril. Paris: Raisons D’ Agir Éditions, 1997.

BARTHES, R. Aula. São Paulo: Cultrix, $7^{a}$. ed., 1997

BOURDIEU, P. Medalha de ouro do CNRS. In: Escritos de educação. (Org. M. A. Nogueira; A. M. Catani). Petrópolis, RJ: Vozes, 10ª . ed. , 2008.

CATANI, A. M.; HEY, A. P. Confluências e disjunções nas políticas de educação superior na América Latina: Argentina, Brasil, Chile e México-ou 4 funerais e 1 união consensual. In: SILVA JR., J. dos R. (Org.). O pragmatismo como fundamento das reformas educacionais no Brasil. Campinas, SP: Editora Alínea, 2007.

CUNHA, L. A. O público e o privado na educação superior brasileira: fronteira em movimento? In: TRINDADE, H. (Org.). Universidade em ruínas na república dos professores. Petrópolis, RJ: Vozes, 1999.

HEY, A. P.; CATANI, A. M. Produção de doutores na área de humanidades; excesso ou má distribuição? Revista ADUSP (Associação dos Docentes da USP). São Paulo, n. 43, p. 56-58, julho, 2008.

LIMA, L. C.; AZEVEDO, M. L. N.; CATANI, A. M. O Processo de Bolonha, a avaliação da educação superior e algumas considerações sobre a Universidade Nova. Avaliação - Revista da avaliação da educação superior. Campinas, SP: RAIES; Sorocaba, SP: Uniso, v. 13, n. 1, p. 7-37, março, 2008.

ROSANVAlLON, P. Por uma historia conceptual de lo político. Buenos Aires: Fondo de Cultura Económica, 2003. 